\title{
XXXI. On impossible equations, on impossible quantities, and on tessarines
}

\author{
James Cockle Esq. M.A.
}

To cite this article: James Cockle Esq. M.A. (1850) XXXI. On impossible equations, on impossible quantities, and on tessarines, Philosophical Magazine Series 3, 37:250, 281-283, DOI: $10.1080 / 14786445008646598$

To link to this article: http://dx.doi.org/10.1080/14786445008646598

册 Published online: 30 Apr 2009.

Submit your article to this journal $[\pi$

Џ Article views: 5

Q View related articles $\square$ 
be stated with reference to that of nitrate of potash, for the selected times, as follows :-

Nitrate of potash, 1 and 2 per cent. solutions . 100

Hydrate of potash, 1 per cent. solution . . . 101.3

Hydrate of potash, 2 per cent. solution . . . 99.4

These experiments at the low temperature concur, therefore, with those made at the higher temperature, in proving that the times of equal diffusion of the two substances have been properly chosen.

[To be continued.]

XXXI. On Impossible Equations, on Impossible Quantities, and on Tessarines. By J AMEs Cockle, Esq., M.A., of Trinity College, Cambridge; Barrister-at-Lare, of the MiddleTemple*.

[Continued from vol, xxxvi. p. 292.]

DEFINITIONS. By an impossible equation is meant an equation which has no root whatever capable of being expressed in terms of the symbols of the ordinary Double Algebra. By an impossible quantity is meant the new species of imaginary by which an impossible equation is supposed to be satisfied.

* Communicated by T. S. Davies, Esq., F.R.S. Lond. and Ed., who adds the following note.

"From my having become accidentally involved in the discussion of ' congeneric surd equations' (though merely from having called the attention of Mr. Horner to Garnier's equation, and not from any contribution of my own towards its elucidation), several of my friends, and some gentlemen who were strangers, have addressed their views on the subject privately to me. Those of Mr. Cockle, from the somewhat close agreement with my own, and from the form suitable for publication in which they were drawn up, I have sent for insertion in the Philosophical Magazine. Most others were put in forms that would have required modification for the purpose; and this I did not feel myself at liberty to make, lest I should fail to express in my own language the exact view of the writers. There is one friend, however, a very eininent analyst, who takes a view directly opposed to these; and he has given me at different times his own explanation of most of the equations that have been hitherto mooted. When I state that, being opposed to his views (the opposition being founded, as $I$ conceive, on the general principles of analysis), and yet having been uniformly unsuccessful in detecting any specific fallacy in his reasoning, I cannot view the question as being settled. On this account it is that I think the discussion should be kept open; and I trust that the gentleman to whom I refer will afford us the benefit of having his 'vein of thought' laid open in his own way. Exceptions and failing cases are always the most instructive subjects of inquiry in every science:--in analysis they always betoken something yet left to be seen or done.

" On one point, however, I wish to be distinctly understood; viz. as not expressing the slightest opinion, at present, on the subject of Quaternions, Tessarines, or any of the inquiries into which $i, j k$ enter." 
As by linear equations, taken in their utmost generality, we are led to contemplate negative quantity; and as by quadratics, cubics, and the higher equations, we are in like manner led to form the notion of unreal quantity; so by surd or irrational equations we may be conducted to the idea of impossible quantity.

Let

$$
\begin{aligned}
& 1+\sqrt{x-4}-\sqrt{x-1}=\mathrm{W}, \\
& 1-\sqrt{x-4}+\sqrt{x-1}=\mathrm{X}, \\
& 1+\sqrt{x-4}+\sqrt{x-1}=\mathrm{Y}, \\
& 1-\sqrt{x-4}-\sqrt{x-1}=\mathrm{Z} .
\end{aligned}
$$

Then, by actual multiplication, we obtain

$$
\begin{aligned}
& 6-2 x+2 \sqrt{x^{2}-5 x+4}=\mathrm{W} . \mathrm{X}, \\
& 6-2 x-2 \sqrt{x^{2}-5 x+4}=\mathrm{Y} . \mathrm{Z} ;
\end{aligned}
$$

and hence, on multiplication and reduction,

$$
4(5-x)=\mathrm{W} . \mathrm{X} . \mathrm{Y} \cdot \mathrm{Z} \text {. }
$$

Let $\mathrm{WXYZ}=\mathrm{V}$, then 5 is the only value of $x$ which satisfies $\mathrm{V}=0$. Hence, no value of $x$ other than 5 can make either of the factors $\mathrm{W}, \mathrm{X}, \mathrm{Y}$, or $\mathrm{Z}$ equal to zero; for, if so, such other value must make one at least of the remaining factors infinite, and we should have to subject $x$ to incompatible conditions.

Now $W=0$ may, by a transposition, be rendered identical with the equation (1) given by Garnier at p. 335 of the second edition of his Aralyse, and is satisfied by the value $x=5$. But $\mathrm{X}=0$ (which may, by transposition, be rendered identical with the equation numbered (2) by Garnier at the page just cited) is not satisfied by that value; at least, not if we consider the symbol $V$ to be such that the quantities included under it are necessarily affected with $(+1)^{2}$. This appears to me to be the true meaning of that symbol of radicality, provided that, in the development of algebra from arithmetic, we adhere as closely as we can to the analogies afforded by the latter science, in the most general form of which (universal arithmetic or arithmetical algebra) all the quantities (i.e. symbolized numbers) employed are, implicitly at least, considered as affected with $(+1)^{2}$. Accordingly I adhered to this view in forming the equation which led me to my Theory of Tessarines, and by which I sought to connect that theory with ordinary algebra. There is no teal loss of generality by thus restricting the symbol $\checkmark$. The root corresponding to the 
affection $(-1)^{2}$ may always be obtained by prefixing the sign - to that of radicality.

Waiving this discussion however for the present, let us adimit that, in the equation $\mathrm{X}=0, x$ may have given to it the value $x=5(-1)^{2}$. Then $\mathrm{X}=0$ is obviously satisfied. But the ordinary double algebra is not relieved from its difficulty. For neither $5(+1)^{2}$ nor $5(-1)^{2}$ will satisfy either $\mathrm{Y}=0$ or $\mathrm{Z}=0$. If, in the above instances, the difficulty is to be evaded, it is only by greatly refining our solution, and, as it has occurred to me, by using expressions of the form $m(+1)^{2}+n(-1)^{2}$, and by following certain rules respecting our reductions, and the signs to be affixed to the radicals. To those who would attempt such a complex and artificial system of solution rather than admit the existence of an impossible equation I may hereafter address some observations. They will however probably find, as I have done, that their attempts are unsatisfactory, and the results not philosophically admissible. But I shall here content myself with remarking, that, by any system of rules, however artificial, the difficulty is only thrown further back. Thus, the equation

$$
\sqrt{x+\sqrt{x+1}}=0
$$

is utterly intractable.

Should the restricted view which I have taken of the symbol $\checkmark$ be deemed ultimately inadmissible, it would not be difficult to frame a new impossible equation, other than that which I have employed in my 'Theory of Tessarines, and which should give us a new imaginary, determined, like the unreal quantities of double algebra, by means of an equation, and so constituting a natural extension of that algebra. In reframing the fundamental equation of the Tessarine Theory, or in adopting one which should give rise to a different theory, geometric interpretation should always be borne in mind, and the uniaxal geometry thence arising would be as direct an application of algebra as that which occurs in interpreting and applying the ordinary double algebra.

2 Pump Court, Temple,

August 30, 1850 .

XXXII. On the Magnetism of Steam. By Reuben Phillips, Esq.

[Continued from vol. xxxvi. p. 511.]

130. THE galvanoscope used in the following experiments 130. I is a modification of that formerly described (2.). Instead of two astatic needles, I have employed one sus- 